\title{
The role of peripheral inflammatory cells in predicting radiation pneumonitis
}

\author{
P. Liu ${ }^{1}$, S. Wang', X. Fang' ${ }^{2}$, Z.D. Gao', W. Shao' ${ }^{1}$, L. Long', Y.C. Zhang3 ${ }^{*}$ \\ ${ }^{1}$ Department of Oncology, Qingdao Hiser Medical Group, Qingdao, China \\ ${ }^{2}$ Qingdao Institute for Food and Drug Control, Qingdao, China \\ ${ }^{3}$ Department of Traumatic Orthopedics, Qingdao Hiser Medical Group, Qingdao, China
}

\section{- Original article}

*Corresponding authors:
Yongchao Zhang, PhD.,
E-mail: zhyc666@126.com
Revised: April 2020
Accepted: June 2020
Int. J. Radiat. Res., April 2021;
19(2): 401-407
DOI: 10.29252/ijr.19.2.401

\section{ABSTRACT}

Background: Radiation pneumonitis (RP) is a common complication of thoracic radiation which affects patients' ability to breathe, limits the deliverable intensity of radiotherapy and impairs clinical outcomes, indicating the need for timely diagnosis and management. The purpose of this study was to determine the predictive capability of two peripheral inflammatory cells for RP. Materials and Methods: A murine RP model was established using SD rats that received a single dose of $20 \mathrm{~Gy}$ thoracic radiation._At 2 and 4 weeks post-radiation, mice were processed to harvest lungs for hematoxylin -eosin (HE) staining and collect blood for flow cytometry analysis. Results: By 2 weeks post-radiation, histopathological changes had occurred in the lungs indicating the onset of RP. Peripheral $\mathrm{CD}_{4} 5^{+} \mathrm{HIS} 48^{+}$granulocytes were significantly increased by the radiation treatment at both the early and later time points $(P<0.05)$. However, we did not observe a statistically significant increase of $\mathrm{CD}_{4} 5^{+} \mathrm{CD} 11 \mathrm{~b} / \mathrm{c}^{+} \mathrm{HIS} 48^{-}$monocytes/macrophages. Conclusion: Our study highlights the possibility that increased levels of peripheral CD $45^{+} \mathrm{HIS}_{4}{ }^{+}$ granulocytes could serve as a predictive indicator of RP. Early detection provides the opportunity for early intervention and therefore, a reduction in the rate and extent of RP.

Keywords: Radiation pneumonitis, granulocytes, monocytes/macrophages, peripheral, prediction.

\section{INTRODUCTION}

Radiation pneumonitis (RP), an acute immune inflammation, is a common and clinically significant toxicity associated with thoracic irradiation (1). It develops in $15-40 \%$ of patients within 6 to 12 weeks of irradiation (2-6), with the main symptom being fever, cough, respiratory dysfunction, chest pain and, rarely, mortality. Without timely interventions such as high-dose glucocorticoid therapy ${ }^{(7,8)}$ and radiation dose adjustment, RP will eventually progress into pulmonary fibrosis and further worsen the patient's health. Therefore, early detection and intervention for RP is extremely important. Currently, diagnosis of RP is mainly symptom-dependent (9-11), meaning that treatment is only available for patients whose
RP has already progressed enough for them to become symptomatic. The identification of individuals who are at high risk for developing RP through the use of an effective early predictor will be critical to reduce the incidence and extent of RP.

Based on the molecular and cellular changes that occur during the pathogenesis of RP $(12,13)$, a few molecules have been proposed as potential predictors for RP, such as inflammatory cytokines $(14,15)$ and serum surfactant protein D (SP-D) (1), in addition to others. However, further research is required to determine the clinical value of these molecular predictors (16). In addition, although the ways in which certain inflammatory cells that are polarized in irradiated lungs contribute to the pathology of RP have been well studied, it remains unclear if 
these cells have any predictive value for RP.

Neutrophils, a subset of granulocytes, are recognized as one of the major cell types involved in acute inflammation (14,17-19). The increased number of neutrophils in bronchoalveolar lavage (BAL) fluid plays a critical role in the development of RP, which is due, in part, to the tissue damage caused by specific neutrophil degranulation products such as neutrophil elastase (NE) $(20,21)$. Additionally, monocytes and macrophages present in BAL fluid also contribute to the progression of RP (14), likely due to the increased production of tumor necrosis factor-alpha (TNF- $\alpha$ ) (22), reactive oxygen species (ROS) and nitric oxide (NO) (23-25), in addition to other products. Accordingly, it is reasonable to hypothesize that inflammatory $\mathrm{CD}^{2} 5^{+} \mathrm{HIS} 48^{+}$granulocytes $(26,27)$ and $\quad \mathrm{CD} 45^{+} \mathrm{CD} 11 \mathrm{~b} / \mathrm{c}^{+}$HIS48- monocytes/ macrophages (28-32) could serve as potential predictive indicators of RP. The markers on these cells include CD45, which is a leukocyte common antigen (L-CA) expressed on all classic immune cells $(33,34)$ and HIS48 and CD11b/c, which are markers of inflammation-associated granulocytes and monocytes/macrophages, respectively.

Unfortunately, the procedure for collecting BAL fluid is complicated and has a poor patient compliance. Accordingly, it would be difficult to achieve widespread clinical application if granulocytes and monocytes/macrophages obtained from BAL fluid were used as indicators. Since blood collection and subsequent testing is more convenient for both healthcare providers and patients, we sought to analyze changes in circulating granulocytes and monocytes/ macrophages after radiation as well as their correlation with RP, and to explore their feasibility as RP predictors. The work presented here will be useful for determining an optimal early RP predictor, which will benefit patients and has the potential for widespread clinical use.

\section{MATERIALS AND METHODS}

\section{Materials and animals}

Alexa Fluor ${ }^{\circledR} 647$ Mouse Anti-Rat CD45 Clone OX
-1, FITC Mouse Anti-Rat Granulocytes Clone HIS48 and Lysing Buffer were obtained from BD Bioscience (US). Anti-CD11b/c antibody [OX42] (ab1211) was obtained from Abcam (UK). Sodium pentobarbital and ethylenediaminetetraacetic acid (EDTA) dipotassium salt were purchased from Sigma (US). All other reagents were purchased from China National Pharmaceutical Group Corporation (China).

SD rats (male, 10-11 weeks old, $\sim 180 \mathrm{~g}$ ) were obtained from the Laboratory Animal Center of Qingdao Institute (China) and housed under specific pathogen-free conditions. All animal studies were conducted in accordance with guidelines from the Laboratory Animal Management and Welfare Ethics Committee [Approval Reference NO. F2016001].

\section{Establishment of the RP rat model}

A total of 24 SD rats were randomly assigned into the control and RP groups. For the RP group, RP was developed via chest radiation. Briefly, rats were fasted for $8 \mathrm{~h}$ and anaesthetized through intraperitoneal injection of $2 \%$ sodium pentobarbital at a dose of $40 \mathrm{mg} /$ $\mathrm{kg}$ prior to radiation. Selective irradiation of the thoracic region was performed at a dose of $20 \mathrm{~Gy}$ (35-39) using a Varian Clinac 21EX accelerator (US) at a dose-rate of $400 \mathrm{MU} / \mathrm{min}$. At 2 and 4 weeks post-radiation, rats were processed to harvest blood samples from the abdominal aorta for flow cytometry and lungs for HE staining.

\section{Flow cytometry}

$100 \mu \mathrm{L}$ of blood samples were stained for 30 minutes at $4^{\circ} \mathrm{C}$ with fluorescent antibodies. Red blood cells were lysed with $2 \mathrm{~mL}$ Lysing Buffer for 10 minutes at room temperature. Cells were then washed during a 5-minute centrifugation at $2000 \mathrm{rpm}$, resuspended in $200 \mu \mathrm{L}$ of PBS $\mathrm{pH}$ 7.4) and filtered using a 100-mm strainer before analysis using a FACSAria II flow cytometer (BD Biosciences, US). Samples that had not been stained were used as the blank control. HIS48+ and $\mathrm{CD} 11 \mathrm{~b} / \mathrm{c}^{+} \mathrm{HIS} 48^{-}$populations were gated on the basis of the $\mathrm{CD} 45^{+}$cells. Data analysis was performed using Flowjo7.6.1.

\section{Statistical analysis}

A Student's $t$-test was used to compare two 
groups when normality and homogeneity of variance assumptions were satisfied. Otherwise, a non-parametric test was applied. Statistical tests were performed using SPSS17.0. A P value of 0.05 was used as the threshold for statistical significance.

\section{RESULTS}

\section{Successful establishment of the RP model}

A number of studies have shown that rat RP models can be successfully built using a radiation dosage of 20 Gy (35-39). Consistent with these reports, rats in radiation groups developed RP, and no accidental deaths occurred throughout the course of the experiment. Histopathological changes in the lungs could be observed using HE staining (figure 1). At 2 weeks post-radiation we observed an increase in the infiltration of neutrophils, macrophages and lymphocytes, thickening of alveolar and vascular endothelium, edema and erythrocytic and fibrinous inflammatory exudates, all of which are clear signs of inflammation and are indicative of the development of RP (figure 1, c). Although the inflammation appeared to subside to some extent by week 4 (figure $1, d$ ), significant pathological changes were still visible. In contrast, the control group displayed normal lung histology throughout the course of the experiment (figure 1 , a \& b).

\section{Radiation induces an increase in $\mathrm{CD}^{+} 5^{+} \mathrm{HIS48}{ }^{+}$ granulocytes in rat peripheral blood}

Because animal models have been shown to be in the early stage of RP around 2-4 weeks

Figure 1. HE staining of lung tissues. (a, b) HE staining of lung sections obtained from the control group at week 2 (a) and week 4 (b). (c, d) HE staining revealing lung inflammation in irradiated rats (RP group) at week 2 (c) and week 4 (d) following radiation. Arrows indicate areas of inflammation. Magnification: $\times 400$, scale bars: $100 \mu \mathrm{m}$.

Int. J. Radiat. Res., Vol. 19 No. 2, April 2021 after irradiation $(40,41)$, we investigated changes in circulating inflammatory cells in rats at 2 and 4 weeks post-radiation. Using flow cytometry, leukocytes stained with anti-CD45 were first gated from total blood cells. Based on this, the two inflammation-associated subsets, granulocytes expressing HIS48 and monocytes/ macrophages expressing CD11b/c were gated and analyzed.

Analysis of the $\mathrm{CD}^{2} 5^{+} \mathrm{HIS} 48^{+}$population (figure $2 \mathrm{a}-\mathrm{d}$, quantified in figure 2 e) showed that at 2 weeks post-radiation, $31.01 \pm 1.90 \%$ and $53.88 \pm 7.80 \%$ of the CD $45^{+}$cells were HIS48+ granulocytes in the blood of control and RP rats, respectively. This result indicates that thoracic radiation led to a significant increase in the amount of peripheral granulocytes in the blood within two weeks $(\mathrm{P}<0.05)$. Notably, the level of $\mathrm{CD}_{4} 5^{+} \mathrm{HIS} 8^{+}$granulocytes seemed to have plateaued by week 2 in RP rats, as the cell count at week $4 \quad\left(58.62 \pm 8.60 \% \mathrm{CD}^{2} 5^{+} \mathrm{HIS} 8^{+}\right.$cells $)$ showed only a minor increase which did not reach statistical significance $(\mathrm{P}>0.05)$.

\section{Analysis of CD45+CD11b/c+HIS48- monocytes/ macrophages in rat peripheral blood}

The second predictive indicator investigated was $\mathrm{CD}_{4} 5^{+} \mathrm{CD} 11 \mathrm{~b} / \mathrm{c}^{+} \mathrm{HIS} 48^{-}$monocytes/ macrophages. However, as shown in figure 3, unlike granulocytes, radiation did not induce an increase of $\mathrm{CD}^{2} 5^{+} \mathrm{CD} 11 \mathrm{~b} / \mathrm{c}^{+} \mathrm{HIS} 48^{-}$cells at week 2 (figure 3, a, b and e) or week 4 (figure 3, c, d and e). The levels of CD $45^{+} \mathrm{CD} 11 \mathrm{~b} / \mathrm{c}^{+} \mathrm{HIS} 48$ - cells were approximately $5 \%$ in each group, with no statistically significant difference found between the control and RP groups ( $\mathrm{P}>0.05)$.

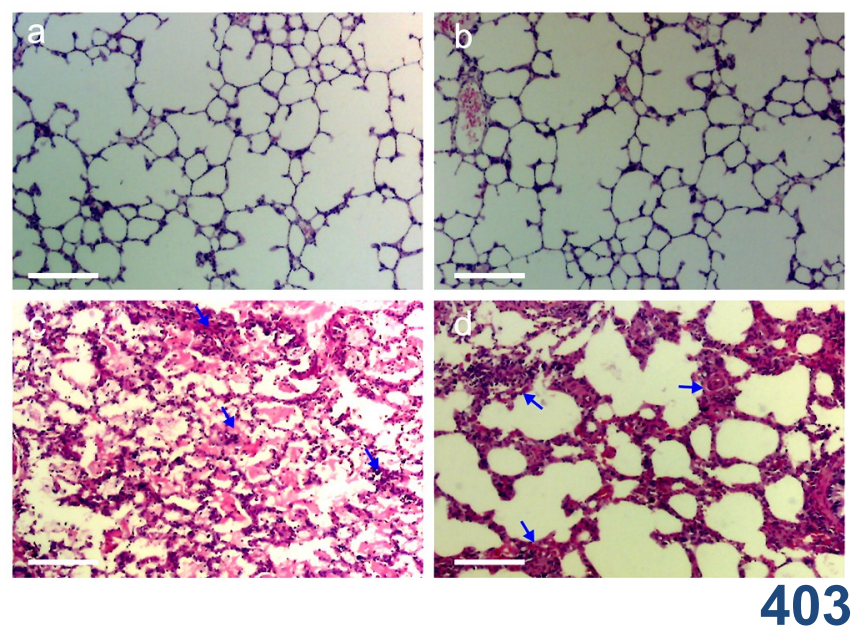




\section{Liu et al. / Peripheral inflammatory cells for radiation pneumonitis prediction}
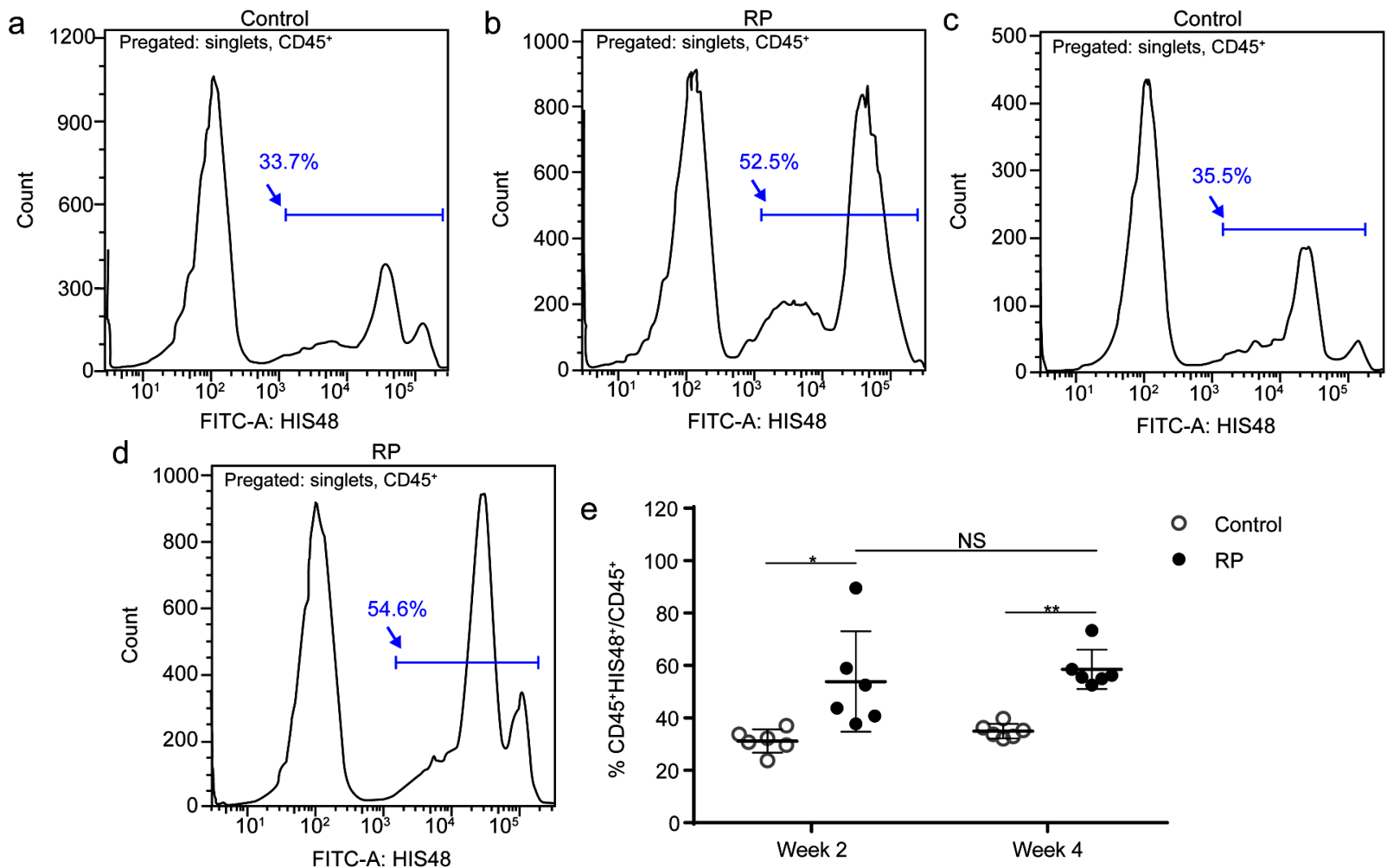

Figure 2. Determination of CD45+HIS48+ granulocytes in rat peripheral blood at 2 and 4 weeks post-radiation. (a-d)

Representative flow cytograms demonstrating changes in the number of CD45+HIS48+ cells at week $2(a, b)$ and week 4 (c, d). Arrows indicate HIS48+ granulocytes gated from pre-gated CD45+ single cells. (e) Quantification of the percentage of CD45+HIS48+ granulocytes in pre-gated $\mathrm{CD} 45+$ leukocytes in each group at the indicated time points. For each group, $n=6, N S: P>0.05,{ }^{*} P<0.05$, $* * \mathrm{P}<0.01$
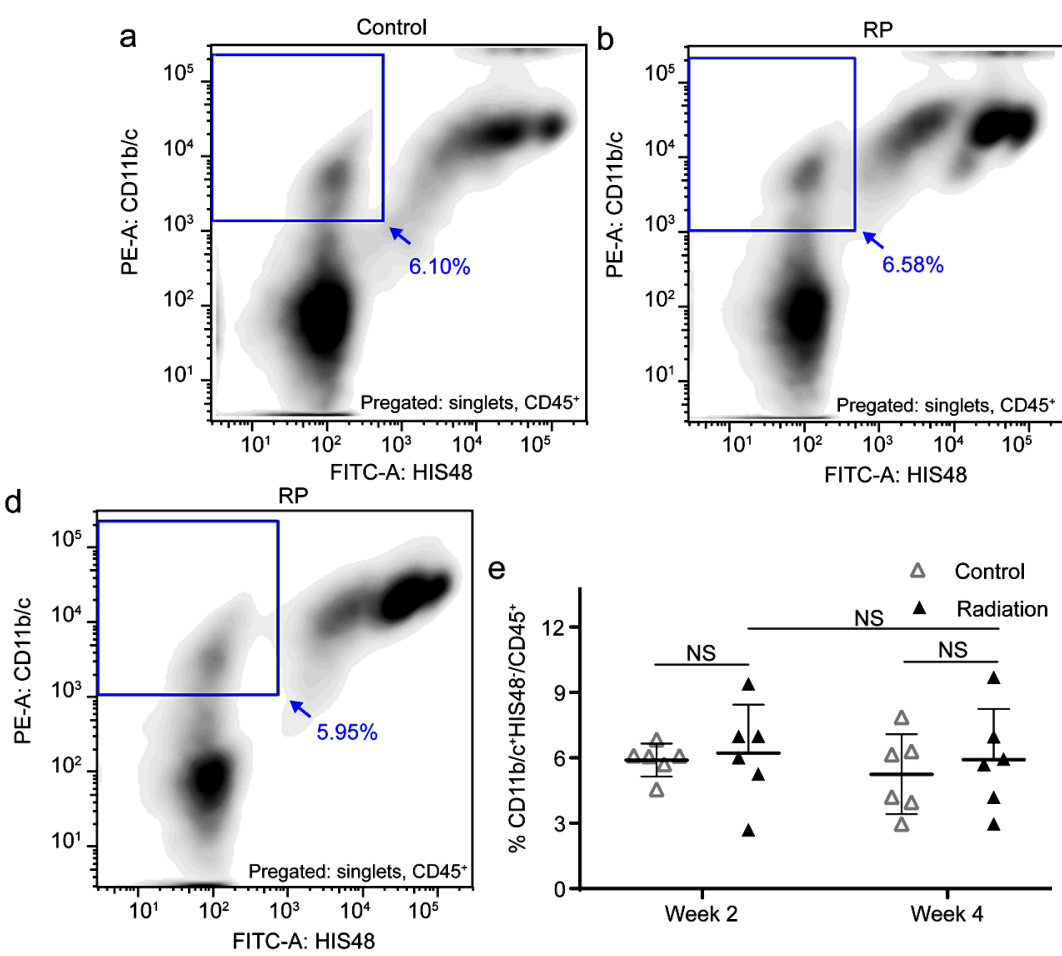

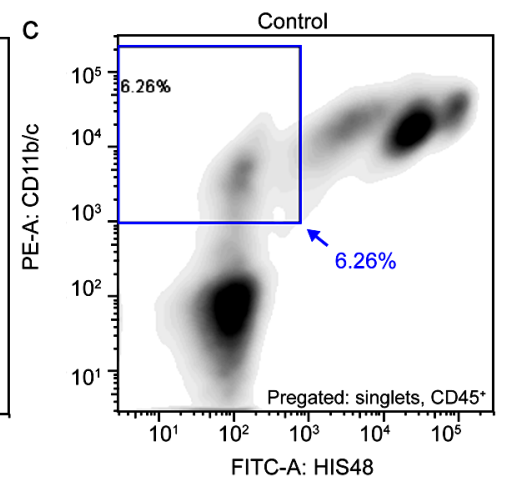

Figure 3. Determination of CD45+CD11b/ c+HIS48- monocytes/macrophages in rat peripheral blood at 2 and 4 weeks postradiation. (a-d) Representative flow cytograms demonstrating changes in the number of CD45+CD11b/c+HIS48- cells at week $2(a, b)$ and week 4 (c, d) Arrows indicate the CD11b/ $\mathrm{c}+\mathrm{HIS} 48$ - monocytes/macrophages gated from CD45+ single cells. (e) Quantification of the percentage of CD11b/c+HIS48- monocytes/ macrophages/CD45+ leukocytes in each group at the indicated time points. For each group, $n=6, N S: P>0.05$. 


\section{DISCUSSION}

It is well known that the increase of BAL fluid granulocytes, one of the biological responses induced by radiation, promotes the progression of RP (42-44). However, our understanding of the correlation between peripheral granulocytes and RP is limited. Here, we show that radiation in rats led to an increase in peripheral granulocytes within two weeks (the early stage of RP). This finding is consistent with a previous report which showed that peripheral neutrophil counts increased over time in patients who ultimately experienced RP (45), indicating that peripheral CD45+HIS48+ granulocytes may be clinically relevant and could serve as a valuable potential predictor of RP. However, the ways in which peripheral granulocytes contribute to the development of $\mathrm{RP}$ requires further exploration.

Prior studies also have established the importance of monocytes/macrophages in RP development $(44,46,47)$. Monocytes/macrophages induce toxic effects through the secretion of cytokines, interleukins, interferons, and NO (48) and the polarization of macrophages in lung tissue has been observed in RP samples $(1,49)$. However, our work indicates that significant, systemic changes of macrophages does not occur during RP development. It is possible that this is because inflammation-associated macrophages were recruited and function locally, leading to a relatively minor change in peripheral blood. An investigation conducted in patients noted an increase in alveolar macrophages in bronchoalveolar lavage fluid, not serum, providing support for this possibility (1). Moreover, as revealed by our work, under normal physiological conditions, monocytes/ macrophages only account for $\sim 5 \%$ of peripheral $\mathrm{CD} 45^{+}$cells analyzed, whereas granulocytes represent $\sim 30 \%$. The possible insensitivity of flow cytometry when analyzing this small cell population may mask minor changes in macrophage content.

Taken together, this article provides evidence supporting the potential use of peripheral $\mathrm{CD}^{2} 5^{+} \mathrm{HIS} 48^{+}$granulocytes as an early predictor of RP. The proposed indicator can easily be

Int. J. Radiat. Res., Vol. 19 No. 2, April 2021 tested in clinics, requiring only two simple processes: a routine blood sample collection and flow cytometry analysis.

\section{CONCLUSION}

A significant increase in peripheral $\mathrm{CD}^{2} 5^{+} \mathrm{HIS} 48^{+}$granulocytes was observed at the early-stage of RP in rats, suggesting the potential value of these cells in predicting the development of RP. This potential predictor can be detected in the blood, which facilitates sample collection for both patients and doctors, and therefore offers significant promise for widespread clinical application.

\section{ACKNOWLEDGEMENT}

This work was supported by Shandong Scientific and Technological Project for Traditional Chinese Medicine [Grant NO. 2015359].

Conflicts of interest: Declared none.

\section{REFERENCES}

1. Yamagishi T, Kodaka N, Kurose Y, Watanabe K, Nakano C, Kishimoto K, Oshio T, Niitsuma K and Matsuse H (2017) Analysis of predictive parameters for the development of radiation-induced pneumonitis. Ann Thorac Med, 12: 252258.

2. Gross NJ (1977) Pulmonary effects of radiation therapy. Ann Intern Med, 86: 81-92.

3. Rodrigues G, Lock M, D'Souza D, Yu E, Van Dyk J (2004) Prediction of radiation pneumonitis by dose - volume histogram parameters in lung cancer--a systematic review. Radiother Oncol, 71: 127-138.

4. Luna JM, Chao HH, Diffenderfer ES, Valdes G, Chinniah C, Ma G, Cengel KA, Solberg TD, Berman AT, Simone CB (2019) Predicting radiation pneumonitis in locally advanced stage II-III non-small cell lung cancer using machine learning. Radiother Oncol, 133: 106-112.

5. Kong FM, Hayman JA, Griffith KA, Kalemkerian GP, Arenberg D, Lyons S, Turrisi A, Lichter A, Fraass B, Eisbruch A, Lawrence TS, Ten Haken RK (2006) Final toxicity results of a radiation-dose escalation study in patients with non- 


\section{Liu et al. / Peripheral inflammatory cells for radiation pneumonitis prediction}

small-cell lung cancer (NSCLC): predictors for radiation pneumonitis and fibrosis. Int J Radiat Oncol Biol Phys, 65: 1075-1086.

6. Schallenkamp JM, Miller RC, Brinkmann DH, Foote T, Garces YI (2007) Incidence of radiation pneumonitis after thoracic irradiation: Dose-volume correlates. Int J Radiat Oncol Biol Phys, 67: 410-416.

7. Bledsoe TJ, Nath SK, Decker RH (2017) Radiation Pneumonitis. Clin Chest Med, 38: 201-208.

8. Murphy R and Vyshedskiy A (2010) Acoustic findings in a patient with radiation pneumonitis. $N$ Engl J Med, 363: e31.

9. Krafft SP, Rao A, Stingo F, Briere TM, Court LE, Liao Z, Martel MK (2018) The utility of quantitative CT radiomics features for improved prediction of radiation pneumonitis. Med Phys, 45: 5317-5324.

10. Farr KP, Kramer S, Khalil AA, Morsing A, Grau C (2015) Role of perfusion SPECT in prediction and measurement of pulmonary complications after radiotherapy for lung cancer. Eur J Nucl Med Mol Imaging, 42: 1315-1324.

11. Rancati T, Ceresoli GL, Gagliardi G, Schipani S, Cattaneo GM (2003) Factors predicting radiation pneumonitis in lung cancer patients: a retrospective study. Radiother Oncol, 67: 275-283.

12. Huang Y, Zhang W, Yu F, Gao F (2017) The Cellular and Molecular Mechanism of Radiation-Induced Lung Injury. Med Sci Monit, 23: 3446-3450.

13. Ghosh SN, Wu Q, Mader M, Fish BL, Moulder JE, Jacobs ER, Medhora M, Molthen RC (2009) Vascular injury after whole thoracic $x$-ray irradiation in the rat. Int J Radiat Oncol Biol Phys, 74: 192-199.

14. Sprung CN, Forrester HB, Siva S, Martin OA (2015) Immunological markers that predict radiation toxicity. Cancer Lett, 368: 191-197.

15. Lee $\mathrm{S}$, Ybarra N, Jeyaseelan K, Faria S, Kopek N, Brisebois P, Bradley JD, Robinson C, Seuntjens J, El Naqa I (2015) Bayesian network ensemble as a multivariate strategy to predict radiation pneumonitis risk. Med Phys, 42: 24212430.

16. Li B, Chen SH, Lu HJ, Tan Y (2016) Predictive values of TNF$\alpha$, IL-6, IL-10 for radiation pneumonitis. Int J Radiat Res, 14: $173-179$.

17. Malik IA, Moriconi F, Sheikh N, Naz N, Khan S, Dudas J, Mansuroglu T, Hess CF, Rave-Frank M, Christiansen $H$, Ramadori G (2010) Single-dose gamma-irradiation induces up-regulation of chemokine gene expression and recruitment of granulocytes into the portal area but not into other regions of rat hepatic tissue. Am J Pathol, 176: 18011815.

18. Yam AO and Chtanova T (2019) Imaging the neutrophil: Intravital microscopy provides a dynamic view of neutrophil functions in host immunity. Cell Immunol, 350: 1-11.

19. Kolaczkowska E and Kubes P (2013) Neutrophil recruitment and function in health and inflammation. Nat Rev Immunol, 13: 159-175.

20. Fox J and Haston CK (2013) CXC receptor 1 and 2 and neutrophil elastase inhibitors alter radiation-induced lung disease in the mouse. Int J Radiat Oncol Biol Phys, 85: 215222.

21. Shimbo $T$, Inomata $T$, Takahashi $M$, Tatsumi $T$, Uesugi $Y$, Narabayashi I, Sonobe H (2007) Effects of sivelestat sodium hydrate on the reduction of radiation pneumonitis. Int J Mol Med, 20: 817-822.

22. Ray D, Shukla S, Allam US, Helman A, Ramanand SG, Tran $L$, Bassetti $M$, Krishnamurthy $P M$, Rumschlag $M$, Paulsen $M$, Sun L, Shanley TP, Ljungman M, Nyati MK, Zhang M, Lawrence TS (2013) Tristetraprolin mediates radiationinduced TNF-alpha production in lung macrophages. PLOS One, 8: e57290.

23. Najafi M, Motevaseli E, Shirazi A, Geraily G, Rezaeyan A, Norouzi F, Rezapoor S, Abdollahi H (2018) Mechanisms of inflammatory responses to radiation and normal tissues toxicity: clinical implications. Int J Radiat Biol, 94: 335-356.

24. Yahyapour R, Motevaseli E, Rezaeyan A, Abdollahi H, Farhood B, Cheki M, Rezapoor S, Shabeeb D, Musa AE, Najafi $M$, Villa V (2018) Reduction-oxidation (redox) system in radiation-induced normal tissue injury: molecular mechanisms and implications in radiation therapeutics. Clin Transl Oncol, 20: 975-988.

25. Wynn TA and Ramalingam TR (2012) Mechanisms of fibrosis: therapeutic translation for fibrotic disease. Nat Med, 18: 1028-1040.

26. de Vos AF, Dick AD, Klooster J, Broersma L, McMenamin $P G$, Kijlstra A (2000) Analysis of the cellular infiltrate in the iris during experimental autoimmune encephalomyelitis. Invest Ophthalmol Vis Sci, 41: 3001-3010.

27. Mirkov I, Popov Aleksandrov A, Demenesku J, Ninkov M, Mileusnic D, Kataranovski D, Kataranovski M (2017) Warfarin affects acute inflammatory response induced by subcutaneous polyvinyl sponge implantation in rats. Cutan Ocul Toxicol, 36: 283-288.

28. Klar AS, Bottcher-Haberzeth S, Biedermann T, Michalak K, Kisiel M, Reichmann E, Meuli M (2014) Differential expression of granulocyte, macrophage, and hypoxia markers during early and late wound healing stages following transplantation of tissue-engineered skin substitutes of human origin. Pediatr Surg Int, 30: 1257-1264.

29. Fecho K, Nelson CJ, Lysle DT (2000) Phenotypic and functional assessments of immune status in the rat spleen following acute heroin treatment. Immunopharmacology, 46: 193-207.

30. Nadella V, Ranjan R, Senthilkumaran B, Qadri S, Pothani S, Singh AK, Gupta ML, Prakash H (2019) Podophyllotoxin and Rutin Modulate M1 (iNOS+) Macrophages and Mitigate Lethal Radiation (LR) Induced Inflammatory Responses in Mice. Front Immunol, 10: 106.

31. Petrescu AD, Grant S, Frampton G, McMillin M, Kain J, Kodali M, Shetty AK, DeMorrow S (2018) Gulf war illnessrelated chemicals increase $\mathrm{CD} 11 \mathrm{~b} / \mathrm{c}(+)$ monocyte infiltration into the liver and aggravate hepatic cholestasis in a rodent model. Sci Rep, 8: 13147.

32. Borthwick LA, Barron L, Hart KM, Vannella KM, Thompson RW, Oland S, Cheever A, Sciurba J, Ramalingam TR, Fisher AJ, Wynn TA (2016) Macrophages are critical to the 
maintenance of IL-13-dependent lung inflammation and fibrosis. Mucosal Immunol, 9: 38-55.

33. Gao H, Henderson A, Flynn DC, Landreth KS, Ericson SG (2000) Effects of the protein tyrosine phosphatase CD45 on FcgammaRlla signaling and neutrophil function. Exp Hematol, 28: 1062-1070.

34. Mitchell GB, Khandaker MH, Rahimpour R, Xu L, Lazarovits Al, Pickering JG, Suria H, Madrenas J, Pomerantz DK, Feldman RD, Kelvin DJ (1999) CD45 modulation of CXCR1 and CXCR2 in human polymorphonuclear leukocytes. Eur J Immunol, 29: 1467-1476.

35. Miyake K, Tani K, Kakiuchi S, Suzuka C, Toyoda Y, Kishi J, Tezuka T, Yuasa S, Hanibuchi M, Aono Y, Nishioka Y, Sone $S$ (2012) Epidermal growth factor receptor-tyrosine kinase inhibitor (gefitinib) augments pneumonitis, but attenuates lung fibrosis in response to radiation injury in rats. $J$ Med Invest, 59: 174-185.

36. Yazici $G$, Yildiz F, Iskit A, Erdemli E, Surucu S, Firat $P$, Hayran M, Ozyigit G, Cengiz M (2011) The effect of vitamin D prophylaxis on radiation induced pulmonary damage. $J$ Radiat Res, 52: 616-621.

37. Osterreicher J, Pejchal J, Skopek J, Mokry J, Vilasova Z, Psutka J, Vavrova J, Mazurova Y (2004) Role of type II pneumocytes in pathogenesis of radiation pneumonitis: dose response of radiation-induced lung changes in the transient high vascular permeability period. Exp Toxicol Pathol, 56: 181-187.

38. Molteni A, Moulder JE, Cohen EF, Ward WF, Fish BL, Taylor JM, Wolfe LF, Brizio-Molteni L, Veno P (2000) Control of radiation-induced pneumopathy and lung fibrosis by angiotensin-converting enzyme inhibitors and an angiotensin II type 1 receptor blocker. Int J Radiat Biol, 76: 523-532.

39. Buttner C, Skupin A, Reimann T, Rieber EP, Unteregger G, Geyer P, Frank KH (1997) Local production of interleukin-4 during radiation-induced pneumonitis and pulmonary fibrosis in rats: macrophages as a prominent source of interleukin-4. Am J Respir Cell Mol Biol, 17: 315-325.

40. Jackson IL, Xu P, Hadley C, Katz BP, McGurk R, Down JD, Vujaskovic Z (2012) A preclinical rodent model of radiation -induced lung injury for medical countermeasure screening in accordance with the FDA animal rule. Health Phys, 103: 463-473.

41. Williams JP, Jackson IL, Shah JR, Czarniecki CW, Maidment BW, DiCarlo AL (2012) Animal models and medical coun- termeasures development for radiation-induced lung damage: report from an NIAID Workshop. Radiat Res, 177: e0025-0039.

42. Huang L, Ogushi F, Tani $K$, Ogawa $H$, Kawano $T$, Endo $T$, Izumi K, Sono N, Ueno J, Nishitani H, Sone S (2001) Thrombin promotes fibroblast proliferation during the early stages of experimental radiation pneumonitis. Radiat Res, 156: 45-52.

43. Ao X, Zhao L, Davis MA, Lubman DM, Lawrence TS, Kong FM (2009) Radiation produces differential changes in cytokine profiles in radiation lung fibrosis sensitive and resistant mice. J Hematol Oncol, 2: 6.

44. Abernathy LM, Fountain MD, Rothstein SE, David JM, Yunker CK, Rakowski J, Lonardo F, Joiner MC, Hillman GG (2015) Soy Isoflavones Promote Radioprotection of Normal Lung Tissue by Inhibition of Radiation-Induced Activation of Macrophages and Neutrophils. J Thorac Oncol, 10: 1703-1712.

45. Zhou $P$, Chen L, Yan D, Huang C, Chen G, Wang Z, Zhong L, Luo W, Chen D, Chun C, Zhang S, Li G (2020) Early variations in lymphocytes and T lymphocyte subsets are associated with radiation pneumonitis in lung cancer patients and experimental mice received thoracic irradiation. Cancer Med, 00: 1-8.

46. S NS, Raviraj R, Nagarajan D, Zhao W (2018) Radiationinduced lung injury: impact on macrophage dysregulation and lipid alteration - a review. Immunopharmacol Immunotoxicol: 1-10.

47. Groves AM, Johnston CJ, Misra RS, Williams JP, Finkelstein JN (2015) Whole-Lung Irradiation Results in Pulmonary Macrophage Alterations that are Subpopulation and Strain Specific. Radiat Res, 184: 639-649.

48. Fujishima $S$, Nakamura $M$, Nakamura $H$, Inoue $T$, Yogo $Y$, Okubo Y, Aikawa N, Kanazawa M, Yamaguchi K (2004) Flow cytometric detection of cell-associated interleukin-8 in alveolar macrophages in-vivo from patients with hypersensitivity pneumonitis and sarcoidosis. Scand J Clin Lab Invest, 64: 237-243.

49. Li Y, Lu H, Lv X, Tang Q, Li W, Zhu H, Long Y (2018) Blockade of Aquaporin 4 Inhibits Irradiation-Induced Pulmonary Inflammation and Modulates Macrophage Polarization in Mice. Inflammation, 41: 2196-2205. 
